\title{
Correlação entre a atipia linfocitária e o perfil imunológico de vacas leiteiras infectadas pelo vírus da leucemia bovina
}

\author{
Correlation between immunological profile and atypical \\ lymphocytes in bovine leukemia virus infected dairy cows
}

\author{
Tatiana Rezende Spinola ${ }^{1}$; Heloisa Godoi Bertagnon ${ }^{2 *}$; Camila Freitas Batista ${ }^{1}$; \\ Fernando Nogueira Souza ${ }^{1}$; Milton Ricardo Azedo ${ }^{3}$; Maiara Garcia Blagitz \\ Fernando José Benesi ${ }^{5}$; Alice Maria Melville Paiva Della Libera ${ }^{5}$
}

\section{Resumo}

O presente trabalho teve o objetivo avaliar a atipia linfocitária, em bovinos da raça Holandesa Preto e Branco naturalmente infectados pelo vírus da leucemia bovina (BLV) correlacionando-a com as duas formas de manifestação da doença, linfocitose persistente (LP) e alinfocitóticos (AL). Assim, foram selecionados 56 animais, que foram divididos em três grupos distintos, sendo eles negativos $(\mathrm{N}, \mathrm{n}=25)$, alinfocitóticos $(\mathrm{n}=12)$ e com linfocitose persistente $(\mathrm{n}=19)$, de acordo com resultados do leucograma e do sorodiagnóstico da Leucose Enzoótica Bovina (LEB) pela imunodifusão em ágar gel e pelo ensaio imunoenzimático. Destes, foram avaliadas as atipias linfocitárias. Em 15 animais, cinco de cada grupo, realizou-se análise de correlação entre as atipias linfocitárias e com os índices de proliferação de linfócitos e apoptose de células $\mathrm{CD}^{+}$. Os resultados deste estudo mostraram que os linfócitos atípicos, e suas diferentes morfologias: sombra de Gümprecht, linfócito monocitóide e linfócito com núcleo duplo, foram encontrados nos três grupos, porém mais comumente em animais infectados pelo BLV, predominantemente no grupo manifestando LP. Na análise da correlação entre a apoptose de células $\mathrm{CD}^{+}$e a porcentagem das populações linfocitárias, observou-se que a apoptose teve correlação negativa com atipia linfocitária. Na correlação entre a proliferação, observou-se que quanto maior a porcentagem de linfócitos, e de linfócitos monocitóides, menor é a proliferação, o que não ocorreu nas demais populações celulares. Portanto, a manifestação da LP em animais naturalmente infectados pelo BLV, pode ser associada ao aumento de linfócitos atípicos, principalmente os do tipo sombra de Gümprecht, linfócito monocitóide e linfócito núcleo duplo.

Palavras-chave: Linfócitos, bovinos, linfocitose persistente, apoptose, proliferação celular

\begin{abstract}
This study aims to evaluate the atypical lymphocyte in Holstein dairy cows in seropositive animals for bovine leukemia virus (BLV) with or without persistent lymphocytosis and in seronegative BLV ones, and correlate them with apoptosis of cells $\mathrm{CD}^{+}$and lymphocyte proliferation. Thus, we selected 56 animals, and divided according to the white blood count and serological response for BLV performed by agar gel immunodiffusion and by enzyme immunoabsorbent assay in: negative ( $N, n=25)$, nonlymphocytic $(A L, n=12)$ and with persistent lymphocytosis $(P L, n=19)$. In these animals, the atypical

\footnotetext{
${ }^{1}$ Discente(s) da Faculdade de Medicina Veterinária e Zootecnia, Universidade de São Paulo, USP, São Paulo, SP. E-mail: tatispinola@uol.com.br; camilafb@usp.br; nogueirasouza@yahoo.com.br

${ }^{2}$ Prof ${ }^{a}$ de Medicina Veterinária, Universidade Estadual do Centro Oeste, UNICENTRO, Guarapuava, PR. E-mail: hgodoi@usp.br

3 Prof. da Faculdade Metropolitanas de Santos, FEFIS, Santos, SP. E-mail: mr.azedo@uol.com.br

${ }^{4}$ Prof $^{a}$ da Faculdade de Medicina Veterinária, Universidade Federal do Paraná, UFPR, Curitiba, PR. E-mail: magblagitz@uol.com.br

${ }^{5}$ Profs. da Faculdade de Medicina Veterinária e Zootecnia, USP, São Paulo, SP. E-mail: febencli@usp.br; dellalibera@usp.br

* Autor para correspondência
} 
lymphocyte was evaluated. 15 animals were selected, five for each group, and they were evaluated for correlation about atypical lymphocyte and lymphocyte proliferation or apoptosis of $\mathrm{CD}^{+}$cells. The results of this study showed that the absolute and relative values of atypical lymphocytes were higher in group PL. Regarding atypical lymphocytes, lymphocytes Gumprecht shadow, lymphocyte and monocytoid lymphocytes with dual core, were found in the three study groups, but more commonly found in animals infected with BLV especially in animals with PL. The apoptosis of $\mathrm{CD}^{+}$cells has a positive correlation with lymphocytes with dual core, which did not occur in other cell populations. The negative correlation between lymphocyte proliferation and monocytoid lymphocytes was observed, which did not occur in other cell populations. Therefore, the animals naturally infected BLV with PL may be associated with increased atypical lymphocytes of the type of shadow Gumprecht, lymphocyte and lymphocyte monocytoid dual-core.

Key words: Lymphocyte, cattle, persistent lymphocytosis, apoptosis, cell proliferation

\section{Introdução}

No inicio do século passado a leucose enzoótica bovina (LEB) foi muito estudada devido a sua alta incidência nas regiões do leste da Europa. Apesar de ter sido erradicada com sucesso de vários países europeus, esta enfermidade ainda apresenta expressiva prevalência no Brasil (D'ANGELINO; GARCIA; BIRGEL, 1998; AZEDO et al., 2011). Embora cause prejuízo econômico mais evidente nos animais que desenvolvem a forma tumoral, 0,1 a $10 \%$ dos animais infectados (COCKERELL; REYES, 2000), a perda de produtividade e restrição no comércio de animais sororreagentes ou de seus produtos, redunda emimpacto econômicoimportante (SCHWARTZ; LEVY, 1994; TIWARI et al., 2007). Ademais, deve-se considerar ainda, que os efeitos da LEB advém não apenas de sua sua letalidade, mas principalmente ao aumento da susceptibilidade a outras enfermidades (VANLEEUWEN et al., 2010; SOUZA et al., 2012).

A afecção é caracterizada por quadro sintomático pleomórfico e alterações hematológicas, que em raros casos, podem evoluir para manifestações tumorais (linfossarcomas), caracterizadas por infiltração mononuclear em órgãos ricos em tecido retículo-histiocitário (BURNY et al., 1985).

As alterações hematológicas permitem a classificação da LEB em animais sem linfocitose (alinfocitóticos - AL) e com linfocitose persistente (LP), encontrada em 30 a $70 \%$ dos bovinos infectados
(GARCIA et al., 1995). Todas as manifestações da afecção podem ser acompanhadas por atipias linfocíticas, já que o vírus da leucemia bovina (VLB) (bovine leukemia virus - BLV), pertencente à família Retroviridae, é um deltaretrovírus tipo $\mathrm{C}$ que afeta, principalmente, os linfócitos B (DELLA LIBERA et al., 2012), integrando ao seu genoma na célula hospedeira, podendo alterar a morfologia da célula (SCHWARTZ et al., 1994; MURAKAMI et al., 2011).

O VLB pode interferir na homeostase do número de linfócitos, que é garantida pelo equilíbrio entre a proliferação e a morte celular (DEBACQ et al., 2002). Assim, a modulação do processo apoptótico, associada ou não ao aumento da proliferação celular, pode refletir no aumento dos linfócitos B circulantes (DELLA LIBERA et al., 2012), que geralmente co-expressam a molécula CD5 e a integrina CD11b, nos animais infectados pelo BLV (DEBACQ et al., 2003; SOUZA et al, 2011). Tal modulação pode ser responsável pela persistência da infecção e/ou pela progressão da enfermidade, ja que as células infectadas que apresentam antígenos virais são reconhecidas e eliminadas pelo hospedeiro constantemente (GILLET et al., 2007; CLARKE; TYLER, 2009). Como o vírus evade-se desta resposta inicial do hospedeiro, supõe-se que haja um balanço entre a infecção de novos linfócitos B e a eliminação de células que expressam antígenos virais, permitindo que o animal permaneça com a infecção (KABEYA; OHASHI; ONUMA, 2001). 
Os linfócitos atípicos são definidos como formas intermediárias da ativação de linfócitos em decorrência de estímulos antigênicos virais. Tais linfócitos apresentam variações nos detalhes morfológicos e nas características dos marcadores de superfície, mostrando constituir uma mistura heterogênea de tipos celulares (SIMON, 2003). Embora a maioria dos linfócitos encontrados em animais sororreagentes para a LEB sejam normais, há informações discrepantes sobre a proporção de suas formas atípicas nas diferentes manifestações da doença, estando muitas vezes associadas à condição pré-leucêmica (GOTZE; ROSENBERGER; ZIEGENHAGEN, 1954), ou mesmo às outras formas da doença não tumoral (WEBER, 1963).

Devido a discrepância entre os dados disponíveis a literatura, este trabalho teve o objetivo de avaliar atipias linfocitárias em vacas com LEB, correlacionando-as com os índices de apoptose e proliferação de linfócitos nas diferentes formas de manifestação da doença, LP e AL, em bovinos da raça Holandesa Preto e Branco naturalmente infectados pelo BLV.

\section{Material e Métodos}

Foram analisadas amostras de sangue de 56 vacas da raça Holandesa sem alterações clínicas evidentes, na mesma fase da lactação e lote de alimentação, subdivididas em três grupos de acordo com os resultados sorológicos e dos leucogramas. O grupo negativo $(\mathrm{N})$ foi composto por 25 animais soronegativos para a VLB sem alterações hematológicas, o segundo grupo foi composto por 12 animais alinfocitóticos (AL), caracterizados por serem sororreagentes para VLB e não apresentarem alterações hematológicas, e o terceiro grupo, denominado com linfocitose persistente (LP), foi formado por 19 animais sororreagentes e com linfocitose, caracterizada por contagem total de linfócitos superior a $10 \times 10^{3} / \mu \mathrm{L}$ e contagem total de leucócitos superior a $15 \times 10^{3} / \mu \mathrm{L}$, conforme critérios estabelecidos por Brenner, Avidar e Lahav (2007).
Aa persistência da linfocitose foi confirmada após um período de 72 dias.

Os testes para o sorodiagnóstico de LEB foram realizados em soro sanguíneo utilizando conjunto comercial de imunodifusão em ágar gel $\left(\right.$ Tecpar $^{\circledR}$, Curitiba, Brasil), e por conjunto comercial de ensaio imunoenzimático (ELISA) (VRMD, Pullman, EUA, $n^{\circ}$ cat. 284-5) por meio da detecção da glicoproteína 51 (gp51) do VLB. Foram considerados animais soronegativos ou soropositivos aqueles que apresentaram resultados iguais nas duas técnicas de diagnóstico sorológico.

O leucograma foi realizado em amostras de sangue com EDTA, sendo o número total de leucócitos por microlitro mensurado por meio de contagem automática $\left(\mathrm{ABC} \mathrm{Vet}^{\mathrm{Q}}-\mathrm{ABX}^{\mathrm{TM}}\right)$. A contagem diferencial foi realizada por meio de esfregaços sanguíneos corados pelo corante de Rosenfeld, sendo classificadas 100 células conforme suas características morfotintoriais em neutrófilos bastonetes, neutrófilos segmentados, eosinófilos, basófilos, linfócitos e monócitos em microscopia óptica de imersão. A morfologia linfocitária foi classificada como típicas ou atípicas, conforme descrito por Birgel (1982), a saber: linfócitos monocitóides (LM); sombras de Grümprecht(SG); linfócitos com núcleo duplo (ND); linfócitos com núcleo picnótico (LPic);e linfócitos plasmocitóides (PLASM) também denominados como células de Türk foram as atipias.

Foram considerados como valores de referência para as contagens leucocitárias dos animais, os dados obtidos por Kramer (2000) e Divers e Peek (2008).

Em amostras de sangue de cinco animais de cada grupo, foram realizadas a proliferação de linfócitos e apoptose de células $\mathrm{CD}^{+}$com a finalidade de correlacionar os índices de atipias aos índices de proliferação de linfócitos e porcentagem de apoptose de células $\mathrm{CD}^{+}$.

O ensaio da proliferação de linfócítos foi realizado com células mononucleares do sangue 
periférico heparinizado (CMSP), isoladas por gradiente de densidade Ficoll-Paque ${ }^{\mathrm{TM}}$ Plus $^{\circledR}$ (GraphPad Software, Inc., San Diego, CA, EUA) (densidade 1, $077 \mathrm{~g} / \mathrm{cm}^{3}$ ), conforme descrito por Souza et al. (2011).

O cálculo da proliferação foi realizado no programa FlowJo, pelo cáuculo de progressão geométrica do decaimento do fluorocromo CFSE das células. Considerou-se que cada célula plaqueada continha $100 \%$ do CFSE fornecido e que, após a mitose restaria $50 \%$ do fluorocromo em cada célulafilha e assim sucessivamente a cada divisão celular (LYONS, 2000; HAWKINS et al., 2007).

A porcentagem de células CD5+ em apoptose foi avaliada utilizando a anexina $\mathrm{V}$ conjugada ao ficoeritrina (FITC) e iodeto de propídio (APOPTESTTM-FITC, Dako Cytomation, Finlândia, cat. K2350), que foram analisados por citometria de fluxo, como descrito por Souza et al. (2011). A identificação da população de células $\mathrm{CD}^{+}$foi realizada utilizando-se anticorpo monoclonal primário: mouse IgG2a anti-bovine CD5 (VRMD, Pullman, EUA, ${ }^{\circ}$. cat. B29A), e anticorpo monoclonal secundário goat anti-mouse IgG2a conjugado ao fluorocromo ficoeritrina (PE) (Invitrogen, Carlsbad, EUA, ${ }^{\circ}$. cat. M32204).

A distribuição de Gaussian foi verificada pelo teste de Kolmogorov e Smirnov. Os dados que apresentaram distribuição paramétrica foram submetidos à análise de variância para verificar as diferenças entre os grupos. Nos casos de diferença significativa, procedeu-se o teste de Tukey-Kramer para comparações múltiplas entre as médias. Os dados que apresentaram distribuição não paramétrica foram submetidos ao teste de KruskallWallis seguido pelo teste de Dunn. Neste caso, os dados foram apresentados em valores medianos. A análise estatística foi realizada utilizando o programa GraphPad Prisma 5.0 software (Minitab Inc., USA). Foram consideradas significativas as análises que apresentaram $\mathrm{P} \leq 0,05$. As correlações entre as diferentes contagens se deram pela correlação de Pearson utilizando o programa MINITAB 16 (Minitab Inc., USA) (SAMPAIO, 1998).

\section{Resultados e Discussão}

Nos grupos N, AL e LP a contagem total de leucócitos foi, respectivamente, de 10,364 x 103/ $\mu \mathrm{L}( \pm 1,355)^{\mathrm{a}}, 10,117 \times 10^{3} / \mu \mathrm{L}( \pm 1,408)^{\mathrm{a}}, 27,968$ $\mathrm{x} 10^{3} / \mu \mathrm{L}( \pm 6,793)^{\mathrm{b}}(\mathrm{P}<0,0001)$, e a contagem total de linfócitos, para os mesmo grupos foi de 6,48 ( \pm $1,34)^{\mathrm{a} ;} 6,88( \pm 1,01)^{\mathrm{a}}, 23,12( \pm 6,92)^{\mathrm{b}} \mathrm{P}=0,0001$.

Sabe-se que os vírus desenvolvem estratégias para neutralizar a resposta apoptótica das células do hospedeiro (SIMON, 2003) e há fortes evidências que a modulação da apoptose na população celular infectada é componente fundamental na persistência viral e na progressão para LP induzida pelo retrovírus (GILLET et al., 2007; SOUZA et al., 2011).

Ao correlacionar as atipias linfocitárias com as formas de manifestação da doença, observou-se que a proporção entre linfócitos atípicos em relação aos linfócitos totais foi maior no LP $\left(10 \%{ }^{\mathrm{b}}\right) \mathrm{em}$ relação aos outros grupos (Negativos - 3,33\%a, $\left.\mathrm{AL}-3,28 \%^{\mathrm{ab}}\right)$. As maiores porcentagem das atipias linfocitárias foram SG (Figura 1), LM (Figura 2) e ND (Figura 3) no LP e ausência de (LPic) e (PLASM) nos três grupos (Figura 4). 
Figura 1. Fotomicrografia do linfócito atípico com sombras nucleares de bovinos em microscopia óptica de Imersão aumento de 100X.

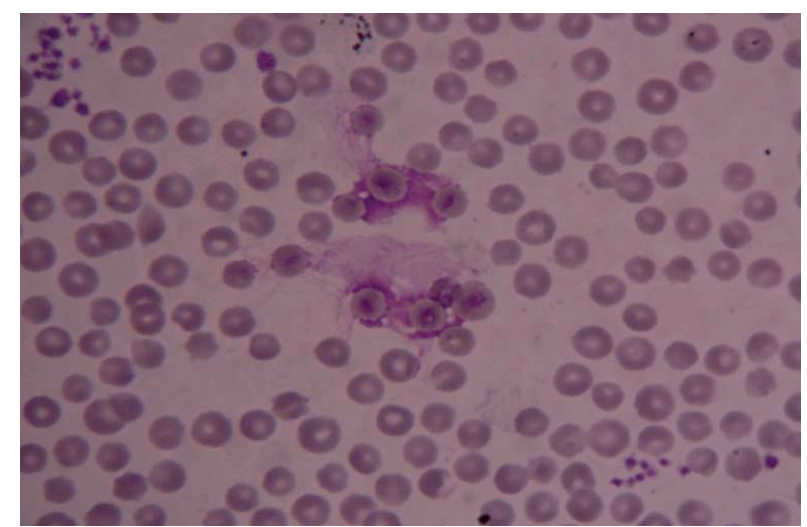

Fonte: Elaboração dos autores.

Figura 2. Fotomicrografia do linfócito atípico do tipo monocitóide bovinos em microscopia óptica de Imersão aumento de 100X.

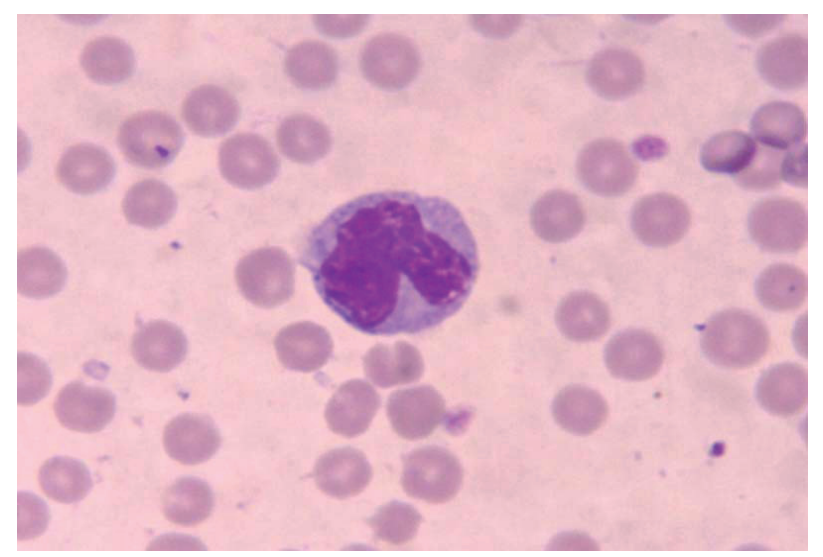

Fonte: Elaboração dos autores.

Figura 3. Fotomicrografia do linfócito atípico do tipo núcleo duplo de bovinos em microscopia óptica de Imersão aumento de $100 \mathrm{X}$.

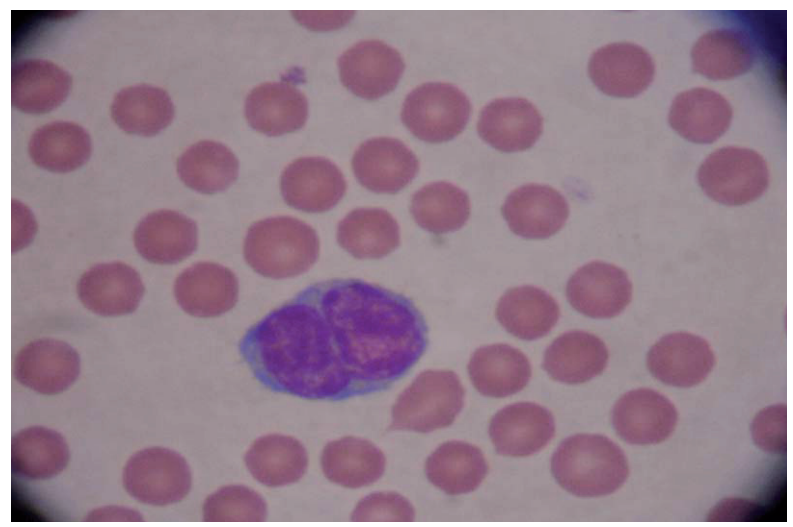

Fonte: Elaboração dos autores.
Figura 4. Valores absolutos da contagem de AL: porcentagem de atipia linfocitária em vacas holandesas nos GN (grupos negativos), GAL (alinfocitótico) e GLP (linfocitose persistente) - São Paulo - 2010.

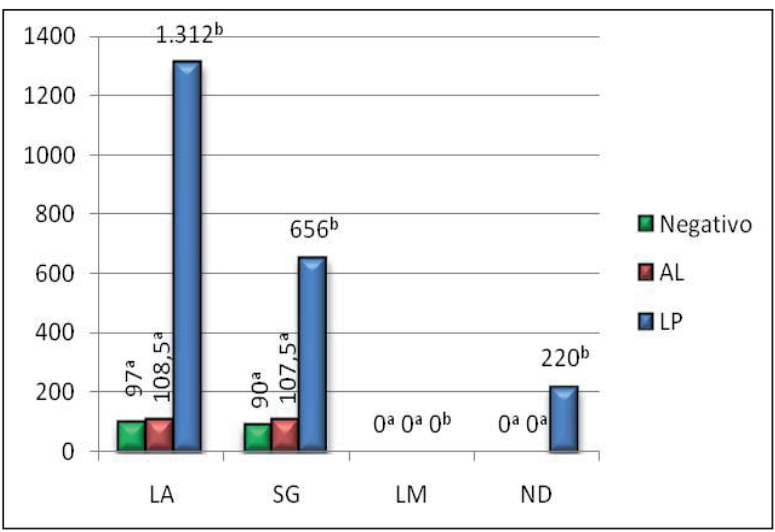

SG: porcentagem de linfócitos apresentando sombras nucleares. LM: porcentagem de linfócitos monocitóides. ND: porcentagem de linfócitos com núcleo duplo.

Fonte: Elaboração dos autores.

Garcia et al. (1991), também encontraram maior proproção de atipias linfocitárias nos animais com LEB, ressaltando que esta caracteristica hematológica é importante para auxiliar o diagnóstico da LEB. Além disto, atipias como SG; Lpic e PLASM foram encontradas tanto em animais soronegativos como sororreagentes para o VLB.

A análise dos índices de proliferação celular com as porcentagens das morfologias das populações linfocitárias, possibilitou observar que a proliferação foi inversamente proporcional a estas variáveis, sendo significativa para os linfócitos totais e LM (Tabela 1).

A análise dos valores relativos da apoptose de células $\mathrm{CD}^{+}\left(\mathrm{CD}^{+} /\right.$anexina $\left.\mathrm{V}-\mathrm{FITC}^{+}\right)$com as porcentagens das morfologias das populações linfocitárias, permitiu observar que a apoptose foi inversamente proporcional a maioria destas variáveis, havendo correlação negativa apenas para o número de linfócitos (Tabela 2). 
Tabela 1. Correlações entre o índice de proliferação celular e a contagem total das populações linfocitárias dos 15 animais considerados positivos para o vírus da LEB utilizados no presente estudo.

\begin{tabular}{ll}
\hline $\begin{array}{l}\text { Linfócitos totais e } \\
\text { Linfócitos atípicos }\end{array}$ & $\begin{array}{l}\text { Índice de correlação } \\
(\mathbf{r}) \mathbf{P}\end{array}$ \\
\hline Linfócitos & $-0,83 \mathrm{P}=0,0001$ \\
$\mathrm{AL}$ & $-0,004 \mathrm{P}=0,10$ \\
$\mathrm{SG}$ & $-0,318 \mathrm{P}=0,25$ \\
$\mathrm{LM}$ & $-0,522 \mathrm{P}=0,046$ \\
$\mathrm{ND}$ & $-0,122 \mathrm{P}=0,7$ \\
\hline
\end{tabular}

AL: porcentagem de atipia linfócitaria. SG: porcentagem de linfócitos apresentando sombras nucleares. LM: porcentagem de linfócitos monocitóides. LP: porcentagem de linfócitos picnóticos. PLASM: porcentagem de linfócitos plasmocitóides. ND: porcentagem de linfócitos com núcleo duplo.

$\mathrm{r}=$ coeficiente de correlação

$\mathrm{P}=$ valor de significância

Fonte: Elaboração dos autores.

Tabela 2. Correlações entre a porcentagem de células $\mathrm{CD}^{+}$do sangue periférico e a apoptose $\left(\mathrm{CD} 5^{+} /\right.$anexina V-FITC $\left.{ }^{+}\right)$ e as porcentagens das populações linfocitárias das 15 vacas holandesa preta e branca, utilizadas no presente estudo.

\begin{tabular}{ll}
\hline Linfócitos totais e & $\begin{array}{l}\text { Índice de correlação } \\
\text { Linfócitos atípicos }\end{array}$ \\
\hline Linfócitos & $-0489 \mathrm{P}=0,064$ \\
$\mathrm{AL}$ & $0,120 \mathrm{P}=0,67$ \\
$\mathrm{SG}$ & $-0,256 \mathrm{P}=0,36$ \\
$\mathrm{LM}$ & $-0,258 \mathrm{P}=0,35$ \\
$\mathrm{ND}$ & $0,402 \mathrm{P}=0,14$ \\
\hline
\end{tabular}

AL: porcentagem de atipia linfocitária. SG: porcentagem de linfócitos apresentando sombras nucleares. LM: porcentagem de linfócitos monocitóides. LP: porcentagem de linfócitos picnóticos. PLASM: porcentagem de linfócitos plasmocitóides. ND: porcentagem de linfócitos com núcleo duplo.

$\mathrm{r}=$ coeficiente de correlação

$\mathrm{P}=$ valor de significância

Fonte: Elaboração dos autores.

Tais achados corroboram com os encontrados por Souza et al. (2011) que observaram que a LP de vacas LEB positivas ocorre por menor proliferação de linfócitos e menor apoptose de células CD5+ do sangue periférico, resultando em maior circulação de células $\mathrm{CD}^{+}$senis.

O provírus do BLV integra o genoma das células infectadas de forma aleatória, e portanto, não transforma as células por mutagênese insercional (KETTMANN et al., 1987), podendo assim alterar mais frequentemente suas organelas, favorecendo o aparecimento de linfócitos atípicos inversamente proporcional à interferência na resposta apoptótica de células infectadas (DEBACQ et al., 2002, 2003; GILLET et al., 2007; SOUZA et al., 2011). Assim, o VLB pode alterar a dinâmica dos linfócitos, perturbando o equilíbrio entre a proliferação celular, diferenciação, morte e/ou recirculação entre o sangue periférico e os órgãos linfóides secundários, resultando nas atipias linfocitárias, principalmente Linfócitos monocitóides (DEBACQ et al., 2002). 


\section{Conclusões}

No presente estudo conclui-se que as atipias linfocitárias, predominam nos animais manifestando LP, embora não sejam exclusivas de animais naturalmente infectados pela VLB. Dentre as atipias linfocitárias mais encontradas, a sombra de Gümprescht, linfócitos monocitóides e linfócitos com núcleo duplo foram as mais comuns. Conclui-se também que a atipia linfocitária tem correlação inversamente proporcional á apoptose e à proliferação linfocitária.

\section{Referências}

AZEDO, M. R.; BLAGITZ, M. G.; SOUZA, F. N.; BENESI, F. J.; DELLA LIBERA, A. M. M. P. Avaliação funcional de monócitos de bovinos naturalmente infectados pelo vírus da leucose bovina. Arquivo Brasileiro de Medicina Veterinária e Zootecnia, Belo Horizonte, v. 63, n. 5, p. 1131-1140, 2011.

BIRGEL, E. H. Leucose enzoótica dos bovinos adultos: aspectos clínicos e diagnóstico. In: BIRGUEL, E. H.; BENESI, F. J. Patologia clínica veterinária. São Paulo: Sociedade Paulista de Medicina Veterinária, 1982. p. $249-60$.

BRENNER, J.; AVIDAR, J.; LAHAV, D. Bovine leukemia virus infection should also be considered in the differential diagnosis of nonspecific clinical manifestations. Israel Journal of Veterinary Medicine, Oxford, v. 62, n. 1, p. 30-31, 2007.

BURNY, A.; BRUCK, C.; CLEUTER, Y.; COUEZ, D.; DESCHAMPS, J.; GREGOIRE, D.; GHYSDAEL, J.; KETTMANN, R.; MAMMERICKX, M.; MARBAIX, G. Bovine leukaemia virus and enzootic bovine leukosis. Onderstepoort Journal of Veterinary Research, PretóriaÁfrica do Sul, v. 52, n. 3, p. 133-144, 1985.

CLARKE, P.; TYLER, K. L. Apoptosis in animal models of virus-induced disease. Nature Reviews Microbiology, Londres, v. 7, n. 2, p. 144-155, 2009.

COCKERELL, G. L.; REYES, R. A. Bovine leukemia virus- associated lymphoproliferative disordes. In: FELDMAN, B. F.; ZINKL, J. G.; JAIN, N. C. (Ed.). Schalm's veterinary hematology. 5. ed. Philadelphia: Lippincott Willians \& Wilkins, 2000. p. 614-619.

D'ANGELINO, J. L.; GARCIA, M.; BIRGEL, E. H. Productive and reproductive performance in cattle infected with bovine leukosis vírus. Journal of Dairy Research, New York, v. 65, n. 4, p.693-695, 1998.

DEBACQ, C.; ASQUITH, B.; KERKHOFS, P.; PORTETELLE, D.; BURNY, A.; KETTMANN, R.; WILLEMS, L. Increased cell proliferation, but not reduced cell death, induces lymphocytosis in bovine leukemia virus-infected sheep. Proceedings of the National Academy of Sciences of the United States of America, Washington, v. 99, n. 15, p. 10048-10053, 2002.

DEBACQ, C.; ASQUITH, B.; REICHERT, M.; BURNY, A.; KETTMANN, R.; WILLEMS, L. Reduced cell turnover in bovine leukemia virus-infected, persistently lymphocytotic cattle. Journal of Virology, Washington, v. 77, n. 24, p. 13073-13083, 2003.

DELlA LIBERA, A. M. M. P.; BLAGITZ, M. G.; FREITAS, C. B.; LATORRE, A. O.; STRICAGNOLO, C. R.; SOUZA, F. N. Quantification of B and T lymphocyte subsets in bovine leukemia virus infected dairy cows. Semina: Ciências Agrárias, Londrina, v. 33, n. 4, p. 1487-1494, 2012.

DIVERS, T. J.; PEEK, S. F. Rebhun's disease of dairy cattle. St. Louis: Saunders Elsevier, 2008.

GARCIA, M.; BASTOS, P. A. S.; BARROS FILHO, I. R.; DELLA LIBERA, A. M. M. P.; COUTINHO, S. D. A.; RAMOS, M. C. C.; LOURENÇO, A.; SILVA, M. M. Efeito da infecção pelo vírus da leucose na ocorrência de mastite em bovinos. A Hora Veterinária, Porto Alegre, v. 15, n. 88, p. 41-44, 1995.

GARCIA, M.; D'ANGELINO, J. L.; BENESI, F. J.; BIRGEL, E. H.; MARÇAL, W. S. Avaliação do leucograma de fêmeas da raça Holandesa naturalmente infectadas pelo vírus da Leucose Bovina. Pesquisa Veterinária Brasileira, Seropédica, v. 11, n. 3-4, p. 6164, 1991.

GILLET, N.; FLORINS, A.; BOXUX, M.; BURTEAU, C.; NIGRO, A.; VANDERMEERS, F.; BALON, H.; BOUZAR, A. B.; DEFOICHE, J.; BURNY, A.; REICHERT, M.; KETTMAN, R.; WILLEMS, L. Mechanisms of leukomogenesis induced by bovine leukemia virus: prospects for novel anti-retroviral therapies in human. Retrovirology, Londres, v. 4, n. 18, p. 1-32, 2007.

GOTZE, R.; ROSENBERGER, G.; ZIEGENHAGEN, G. Die leukose des rindes. inre hämatologische und klinische diagnose. Monatshefte für Veterinärmedizin, Munique, v. 9, n. 2, p. 517-526, 1954. 
HAWKINS, E. D.; HOMMEL, M.; TURNER, M. L.; BATTYE, F. L.; MARKHAM, J. F.; HODGKIN, P. D. Measuring lymphocyte proliferation, survival and differentiation using CFSE time-series data. Nature Protocols, Nova Iorque, v. 2, n. 9, p. 2057-2067, 2007.

KABEYA, H.; OHASHI, K.; ONUMA, M. Host immune responses in the course of bovine leukemia virus infection. Journal of Veterinary Medical Science, Tokio, v. 63, n. 7, p. 703-708, 2001.

KETTMANN, R.; COUEZ, D.; GRÉGOIRE, D.; BURNY, A. Leukemogenesis by Bovine Leukemia Virus. In: BURNY, A.; MAMMERICKX, M. (Ed.). Enzootic bovine Leukosis and bovine Leukemia virus. Boston: Martinus Nijhoff, 1987. p. 153-160.

KRAMER, J. W. Normal hematology of cattle, sheep, and goats. In: FELDMAN, B. F.; ZINKL, J. G.; JAIN, N. C. (Ed.). Schalm's veterinary hematology. 5. ed. Philadelphia: Lippincott Williams \& Wilkins, 2000. p. 1075-1084.

LYONS, A. B. Analysing cell division in vivo and in vitro using flow cytometric measurement of CFSE dye dilution. Journal of Immunological Methods, Nova Iorque, v. 243, p. 147-154, 2000.

MURAKAMI, H.; YAMADA, T.; SUZUKI, M.; NAKAHARA, Y.; SUZUKI, K.; SENTSUI, H. Bovine leukemia virus integration site selection in cattle that develop leukemia. Virus Reserach, Madri, v. 156, n. 1-2, p. 107-112, 2011.

SAMPAIO, J. B. M. Estatística aplicada à experimentação. Belo Horizonte: Fundação de Ensino e Pesquisa em Medicina Veterinária e Zootecnia, 1998. $221 \mathrm{p}$.

SCHWARTZ, I.; BENSAID, A.; POLACK, B.; BERTHELEMY, M.; LEVY, D. In vivo leukocyte tropism of bovine leukemia virus in sheep and cattle. Journal of Virology, Washington, v. 68, n. 7, p. 4589-96, 1994.
SCHWARTZ, I.; LEVY, D. Pathobiology of bovine leukemia virus. The Veterinary Research, Les Ulis Cedex, França, v. 25, n. 6, p. 521-36, 1994.

SIMON, M. W. The atypical lymphocyte. Int Pediatr., Miame, v. 18, n. 1, p. 20-22, 2003.

SOUZA, F. N.; BLAGITZ, M. G.; LATORRE, A. O.; RAMOS SANCHEZ, E. M.; BATISTA, C. F.; WEIGEL, R. A.; RENNÓ, F. P.; SUCUPIRA, M. C. A.; DELLA LIBERA, A. M. M. P. Intracellular reactive oxygen species production by polymorphonuclear leukocytes in bovine leukemia virus-infected dairy cows. Journal of Veterinary Medical Science, Tokyo, v. 74, n. 2, p. 221 225, 2012.

SOUZA, F. N.; LATORRE, A. O.; CANICEIRO, B. D.; SAKAI, M.; KIELING, K.; BLAGITZ, M. G.; DELLA LIBERA, A. M. M. P. Proliferação de linfócitos e apoptose de células CD5+ de bovinos infectados pelo vírus da leucose enzoótica bovina. Arquivo Brasileiro de Medicina Veterinária e Zootecnia, Belo Horizonte, v. 63, n. 5, p. 1124-1130, 2011.

TIWARI, A.; VANLEEUWEN, J.A.; DOHOO, I. R.; HADDAD, J. P.; TREMBLAY, R.; SCOTT, H. M.; WHITING, H. Production effects of pathogens causing bovine leukosis, bovine viral diarrhea, paratuberculosis, and neosporosis. Journal of Dairy Science, Savoy, v. 90, n. 2, p. 659-669, 2007.

VANLEEUWEN, J. A.; HADDAD, J. P.; DOHOO, I. R.; KEEFE, G. P.; TIWARI, A.; SCOTT, H. M. Risk factors associated with Neospora caninum seropositivity in randomly sampled Canadian dairy cows and herds. Preventive Veterinary Medicine, Colorado, v. 93, n. 2-3, p. 129-138, 2010.

WEBER, W. T. Hematologic aspects of bovine lymphosarcoma. Annals of the New York Academy of Science, New York, v. 108, n. 1, p. 1270-1283, 1963. 